\title{
Psychological Stress among Parents of Hearing Impaired versus Intellectually Disabled Pakistani Children
}

\author{
Nazia Firdous ${ }^{1}$, Nazia Mumtaz², Ghulam Saqulain ${ }^{3}$ \\ ${ }^{1}$ Speech \& Language Pathologist, Government Special Education Centre, Phalia, M.B Din, Pakistan \\ ${ }^{2}$ Head of Department of SLP \& Hearing Sciences, Isra Institute of Rehab Sciences, Isra University, Islamabad, Pakistan \\ ${ }^{3}$ Head, Department of Otorhinolaryngology, Capital Hospital, Islamabad, Pakistan
}

\begin{abstract}
A B S T R A C T
Background: Parents of special children face physical, psychological and social impact of their child's disability, including hopelessness and depression. This study is important as it will help professionals plan and provide effective coping strategies so parents could have a positive perception and behavior for disabilities (like hearing impaired and intellectual disability) in their children. The objective of this study was to analyze level of psychological stress among parents of children with hearing impaired $(\mathrm{HI})$ versus intellectual disability (ID) and relationship between disability and psychological stress.

Material and Methods: This cross-sectional study comprised of parents $(n=200)$ of $100 \mathrm{HI}$ and $100 \mathrm{ID}$ children, of both genders, aged 1 to 16 years. These were recruited by non-probability convenience sampling after taking consent from special education centers of Punjab (Pakistan), over a period of six months from May 2017 to October 2017. After collecting demographic details, quantitative assessment of parental stress was done using Parental Stress Scale (PSS). Statistical analysis was carried out using SPSS v21.

Results: The sample population $(n=200)$ consisted of $32.5 \%$ male and $67.5 \%$ female respondents, with a mean age of $41.23 \pm 6.7$ years. The mean of total parental psychological stress score was $61.85 \pm 17.1$ with significant association between disabilities $(\mathrm{HI}$ and ID) and psychological stress $(p<0.01)$. In $H I$ group, moderate psychological stress was seen $(n=53,26.5 \%)$, while in ID group, profound level of psychological stress was noted in majority ( $n=70,35 \%$ ) of participants.

Conclusions: Parents of both $\mathrm{HI}$ and ID children showed psychological stress, however, parents of ID children suffered higher level of stress.

Key words: Hearing impairment, Intellectual disability, Psychological stress, Quality of life

Authors' Contribution: Correspondence: Article info:

1,2 Conception, synthesis, planning of research Ghulam Saqulain Received: August 8, 2019

and manuscript writing Interpretation, discussion, Email:ghulam_saquain@yahoo.com_Accepted: November 23,2019

3. Active participation in data collection

Data analysis.
\end{abstract}

Cite this article. Firdous N, Mumtaz N, Saqulain G. Psychological Stress among pare nts of he aring impaired versus intellectually disabled Pakistani children. J Islamabad Med Dental Coll. 2019; 8(4): 176180. Doi: $10.35787 / j i m d c . v 814.282$

Funding Source: Nil Conflict of Interest: Nil

\section{Introduction}

Disability is associated with lot of stress, especially for the parents and caregivers, resulting in physical, psychological and social impact thus affecting normal functioning ${ }^{1}$ and quality of life (Qol). ${ }^{2}$ Parents with hearing impaired (HI) and intellectually disabled (ID) children, are also affected. According to Pipp-Siegel etal mothers of $\mathrm{HI}$ children, with low family income and lacking social support face higher stress level. ${ }^{3}$ They also suffered from hopelessness and depression, as a result their Qol is affected. ${ }^{4} \mathrm{HI}$, being one of the most common invisible disabilities prevailing in developing countries, marring social and communication development, is a critical event and a source of stress for parents and caregivers, which is also related to the duration of disability. ${ }^{5} \mathrm{HI}$ can occur with other comorbidities like ID. The Diagnostic and Statistical Manual of Mental Disorders-5 (DSM-5), describes intellectual disabilities as disorder of neurodevelopmental onset originating in childhood, with difficulties in conceptual, social and practical areas of life. ${ }^{6}$ ID commonly occurs in the first two decades of life ${ }^{6}$, 
resulting in adaptation problems for the disabled child and mental stress for the caregivers. ${ }^{7}$ The birth, care and upbringing of an ID child in the family, can turn into a threat to the emotional health of parents/ caregiver. A high proportion of parents of such children face anxiety, depression ${ }^{8}$, distress, frustration, powerlessness, and hostility. ${ }^{9}$

A local study, Mumtaz et al. reported that parents of children with hearing loss identified at an earlier stage were more satisfied. ${ }^{10}$ With joint family system still prevalent in the country, compared to nuclear families in the western society and with late identification of $\mathrm{HI}$ with a prevalence of $48 \%$ at $19-24$ months of age ${ }^{11}$, there is possibility of parental stress level being quite different from western societies.

Therefore, the current study was planned with the aim to analyze the level of parental stress among parents of $\mathrm{HI}$ versus ID children and relationship between disability and psychological stress. This could help our speech language pathologists and psychologists in enhancing diagnostic, interventional and management approaches and in turn help provide effective coping strategies so parents could have a positive perception and behavior for disabilities like $\mathrm{HI}$ and ID in their children. The current study is imperative since there is dearth of literature on this important issue and very few studies from this part of the world.

\section{Material and Methods}

This cross-sectional study was carried out over a period of six months from May 2017 to October 2017. A formal approval was taken from school heads to conduct the research at the respective special education centers in Punjab, Pakistan. Ethical committee approval for study was obtained from Isra university and consent was obtained from all the participants prior to enrollment. It includes a study population of 200 participant (parents) calculated using Raosoft application with response distribution at $50 \%$ and population size on 20,000 at $90 \%$ confidence level and $5.76 \%$ margin of error. A total of 100 parents of $\mathrm{HI}$ and 100 parents of ID children visiting the special school in Punjab Pakistan satisfying the selection criteria were recruited in the study. These children belonged to both genders aged 1-16 years. Sampling technique was non-probability convenience sampling. The sample parents belonged to both genders belonging to age group 25 to 60 years. Following informed written consent and filling of basic demographic sheet, parents were asked to fill PSS questionnaire to examine their functional, emotional and phycological problems.

Data was collected and tabulated using Microsoft Excel Worksheet and analyzed using SPSS v 21. Continuous data was presented as mean and standard deviation (SD) while categorical results were calculated as frequency and percentage. To determine relationship between disability and psychological stress, independentt test and chi square tests were applied. $P$ value of $\leq 0.05$ was interpreted as statistically significant.

\section{Results}

Our study population comprised of a total of 200 parents, 100 parents of $\mathrm{HI}$ and 100 parents of ID children, who consented for the inclusion in the study and met the selection criteria. The age range of the study population was 25 to 60 years with mean age of $41.04 \pm 6.59$ years in the HI group and $41.42 \pm 6.86$ years in the ID group, of which $32.5 \%(\mathrm{n}=65)$ were males (33 in $\mathrm{HI}$ and 32 in ID group) and $67.5 \%(n=135)$ were females $(67$ in $\mathrm{HI}$ and 68 in ID group) with male: female ratio of $1: 2.07$. The sample of the two groups (HI vs ID) was kept balanced to avoid any gender and age bias in the study.

The mean of total parental psychological stress score was $61.85 \pm 17.1$. A statistically significant association was found between type of disability ( $\mathrm{HI}$ and ID) and psychological stress with much higher PSS score in parents of ID as compared to $\mathrm{HI}$. It indicates that parents of ID children were facing much more stress than $\mathrm{HI}$ (Table I). Regarding levels of psychological stress, majority of parents of hearing-impaired children had moderate level of psychological stress, while most of parents of ID children had profound level of psychological stress (Table I). 


\begin{tabular}{|c|c|c|c|}
\hline \multicolumn{4}{|c|}{$\begin{array}{l}\text { Table I: Psychologicalstress among study participants } \\
\text { suffering from hearing impairment and intellectual disability } \\
\qquad(n=200)\end{array}$} \\
\hline Variables & $\begin{array}{l}\text { Hearing } \\
\text { impaired group } \\
(n=100) \\
\text { Mean } \pm \text { SD }\end{array}$ & $\begin{array}{c}\text { Intellectual } \\
\text { disability group } \\
(n=100) \\
\text { Mean } \pm \text { SD }\end{array}$ & $\begin{array}{c}{ }^{*} P \text { - } \\
\text { value }\end{array}$ \\
\hline $\begin{array}{l}\text { Mean of } \\
\text { Psychological } \\
\text { stress }\end{array}$ & $47.73 \pm 10.09$ & $75.98 \pm 9.13$ & 0.001 \\
\hline $\begin{array}{l}\text { Levels of } \\
\text { Psychological } \\
\text { stress }(0-100)\end{array}$ & $n(\%)$ & $\mathrm{n}(\%)$ & \\
\hline Mild (0-25) & $03(1.5)$ & 0 & 0.001 \\
\hline $\begin{array}{l}\text { Moderate (26- } \\
50)\end{array}$ & $53(26.5)$ & $26(13)$ & \\
\hline Severe (51-75) & $44(22)$ & $70(35)$ & \\
\hline $\begin{array}{l}\text { Profound (76- } \\
100)\end{array}$ & 0 & $4(2)$ & \\
\hline
\end{tabular}

${ }^{*} P \leq 0.05$ was considered statistically significant

\section{Discussion}

The birth of a hearing impaired or intellectually disabled child affects the dynamics and interaction of the whole family. In this study, parents of both categories showed a significantly high level of psychological stress and there was significant correlation between both types of disability $(\mathrm{HI}$ and $\mathrm{ID})$ and psychological stress $(\mathrm{p}<0.01)$. Studies show that parental stress is significantly higher in parents of children with disabilities ${ }^{12}$, and other factors. ${ }^{13}$ According to Person and Chan, mothers of children with learning disabilities are highly stressed compared to normal children. ${ }^{14}$

In this study, parents of children had significantly different levels of stress among two different etiologic groups of $\mathrm{HI}$ and ID. Most of the parents of children with $\mathrm{HI}(\mathrm{n}=53$, $26.5 \%$ ) exhibited significant, but moderate level of stress. These results are consistent with the work of different researchers. Dehkordi et al. found significantly higher level of stress in mothers of $\mathrm{HI}$ compared to other disabilities. ${ }^{15}$ According to Vinayak et al., mothers of the $\mathrm{HI}$ children had high level of hopelessness and depression, which was adversely affecting their quality of life. ${ }^{4}$ Van Driessche et al. also found higher level of psychological morbidities and strain in parents/caregivers of HI. ${ }^{16}$ Other authors have also reported higher stress levels in parents of $\mathrm{HI}$ children.5,17,18 Spahn et al. found that $21 \%$ parents of cochlear implant $(\mathrm{Cl})$ using children suffered from higher level of stress. ${ }^{19}$ Sarant and Garrard, found negative correlation between parents' stress level and language outcome in $\mathrm{Cl}$ cases with parents of children with bilateral $\mathrm{Cl}$ being less stressed than unilateral $\mathrm{Cl}^{20}$

In our study, $35 \% \quad(n=70)$, parents of intellectually challenged children were suffering from profound level of psychological stress with mean score of $75.98+$ SD 9.126. Similarly, Sheikh et al. found significant levels of parental depression and anxiety in $70 \%$ cases. ${ }^{21}$ Chouhan et al. found statistically significant relationship between parenting stress and anxiety among parents of children with ID. They further noted that parents of children with profound level of ID had more stress compared to parents of children with borderline disability and normal children.$^{22}$ Also, Tsai and Wang found extreme levels of strain in mothers of ID children.23 McConnell and Savage also found higher level of psychological distress as well as family dysfunction in parents of ID children. ${ }^{24}$

One of the findings from current study was parents of children with ID had significantly severe to profound levels of psychological stress as compared to parents of children with $\mathrm{HI}$. This finding is consistent with a Jordanian study reporting highest level of stress in parents of physical disabilities, followed by mental disabilities and lowest in parents of children with $\mathrm{HI}^{25}$

The coping strategies may help reduce the stress associated with disabilities. The findings in a study by Movallai et al. suggest a positive role of behavioral training, especially in reducing maternal psychological problems of $\mathrm{HI}$ children. ${ }^{26}$ This can thus result in good mental health in parents and indirectly improve the Qol of $\mathrm{ID}$ and $\mathrm{HI}$ children. However further research is required to explore the stressors and coping mechanisms for families as a whole and parents in particular, to deal more effectively with children disabilities

\section{Conclusion}

Majority of the parents, of children with both disabilities i.e., $\mathrm{HI}$ and ID, suffer high level of psychological stress with parents of ID having more stress than parents of $\mathrm{HI}$ children. 


\section{References}

1. Gupta VB, Mehrotra P, Mehrotra N. Parental stress in raising a child with disabilities in India. Disability, CBR \& Inclusive Development. 2012; 23(2): 41-52. doi 10.5463/DCID.v23i2.119

2. Sreekeerthi D, Kumar M. A Comparative Study of Quality of Life in Caregivers of Mental Retardation and Normal Children. Sch J App Med Sci. 2017; 5(9D): 3793-98. doi: 10.21276/sjams.2017.5.9.56

3. Pipp-Siegel S, Sedey AL, Yoshinaga-Itano C. Predictors of parental stress in mothers of young children with hearing loss. J Deaf Stud Deaf Educ. 2002; 7(1): 1-17. Doi: 10.1093/deafed/7.1.1

4. Vinayak S, Dhanoa SK, Vinayak R. Relationship of Hopelessness, Depression and Quality of Life in Mothers of Persons with Disabilities. IJIAS. 2016; 17(1): 306-11.

5. Meinzen-Derr J, Lim LH, Choo DI, Buyniski S, Wiley S. Pediatric hearing impairment caregiver experience: Impact of duration of hearing loss on parental stress. Int J Pediatr Otorhinolaryngol. 2008; 72(11): 1693703. Doi: 10.1016/j.jporl.2008.08.005

6. Boat TF, Wu JT, editors. Mental Disorders and Disabilities Among Low-Income Children - Clinical Characteristics of Intellectual Disabilities. Washington (DC); National Academies Press (US); 2015.

7. Chaudhury S. Anxiety and depression in mothers of deaf children: Awareness needed. Med. J. DY Patil Univ. 2014; 7(6): 720-21.

8. Azeem MW, Dogar IA, Shah S, Cheema MA, Asmat A, Akbar $\mathrm{M}$ et al. Anxiety and Depression among Parents of Children with Intellectual Disability in Pakistan. J Can Acad Child Adolesc Psychiatry. 2013; 22(4): 290 - 95. PMID: 24223048

9. Burger T, Spahn C, Richter B, Eissele S, Löhle E, Bengel J. Parental Distress: The Initial Phase of Hearing Aid and Cochlear Implant Fitting. Am Ann Deaf. 2005; 150(1): 5-10. Doi: 10.1353/aad.2005.0017

10. Mumtaz N, Habibullah S, Shafqat F, Aftab A. Benefits of early detection among hearing impaired children: Contemporary parental response. Int J Rehabil Sci. 2016; 5(2): 58-61.

11. Mumtaz N, Habibullah S. Better late than never: Identification of children with Hearing Loss in Pakistan. Pak Armed Forces Med J 2017; 67 (2): 29295.
12. Nadeem M, Choudhary FR, Parveen A, Javaid F. Parental Stress among Parents of Children with and without Disabilities. PJSS. 2016; 36(2):1281-89.

13. Katkić LO, Morović ML, Kovačić E. Parenting Stress and a Sense of Competence in Mothers of Children with And Without Developmental Disabilities. Croatian Review of Rehabilitation Research. 2017; 53(Supplement): 63-76.

14. Pearson V, Chan TW. The relationship between parenting stress and social support in mothers of children with learning disabilities: A Chinese experience. Soc Sci Med. 1993; 37(2):267-74. Doi: 10.1016/0277-9536(93)90461-C

15. Dehkordi MA, Kakojoibari AA, Mohtashami T, Yektakhah S. Stress in mothers of hearing-impaired children compared to mothers of normal and other disabled children. Audiol. 2011; 20(1): 128-36.

16. van Driessche A, Jotheeswaran AT, Murthy GV, Pilot E, Sagar J, Pant H, et al. Psychological well-being of parents and family caregivers of children with hearing impairment in south India: influence of behavioural problems in children and social support. Int Rev Psychiatry. 2014; 26(4): 500-7. doi: 10.3109/09540261.2014.926865

17. Abbas $F$, Rafque $U$, Majid $S$. Stress level of parents of hearing-impaired children. J Educ Pract. 2013; 4(26): 69-77.

18. Lederberg AR, Golbach T. Parenting stress and social support in hearing mothers of deaf and hearing children: A longitudinal study. J Deaf Stud Deaf Educ. 2002; 7(4): 330-45. Doi: 10.1093/deafed/7.4.330

19. Spahn, C, Burger T, Löschmann C, Richter B. Quality of life and psychological distress in parents of children with a cochlear implant. Cochlear Implants Int.2004; 5(1): 13-27. Doi: 10.1080/14670100.2004.11873747

20. Sarant J, Garrard P. Parenting Stress in Parents of Children with Cochlear Implants: Relationships among Parent Stress, Child Language, and Unilateral Versus Bilateral Implants. J Deaf Stud Deaf Educ. 2014; 19(1): 85-106. Doi:10.1093/deafed/ent032

21. Sheikh MH, Ashraf $S$, Imran N, Hussain S, Azeem MW. Psychiatric Morbidity, Perceived Stress and Ways of Coping Among Parents of Children with Intellectual Disability in Lahore, Pakistan. Cureus. 2018; 10(2): e2200. Doi:10.7759/cureus.2200.

22. Chouhan SC, Singh P, Kumar S. Assessment of stress and anxiety in parents of children with intellectual disability. IJHW. 2016; 7(5): 500-04.

23. Tsai SM, Wang HH. The relationship between caregiver's strain and social support among mothers 
with intellectually disabled children. J Clin Nurs. 2009; 18(4): 539-48.

24. McConnell D, Savage A. Stress and resilience among families caring for children with intellectual disability: expanding the research agenda. Curr Dev Disord Rep. 2015; 2(2): 100-09. Doi 10.1007/s40474-0150040-z:

25. Bawalsah JA. Stress and Coping Strategies in Parents of Children with Physical, Mental, and
Hearing Disabilities in Jordan. J. Educ.2016; 8(1): 122. Doi: $10.5296 /$ ije.v8i1.8811

26. Movallali G, Amiri M, Afrashteh MY, Morovati Z. Parental Stress and Mental Health in Mothers of Children with Hearing Impairment: The Effectiveness of a Behavioral Training Program. IOSR-JHSS. 2015; 20(7):89-95 